\title{
Sustainability in Road Construction: Using Bamboo Straw Ash to Improve the Index Properties of Lateritic Soil
}

\author{
${ }^{1(\mathrm{a})}$ BUSARI Ayobami, (1b)Oyedepo, Joseph, ${ }^{2(\mathrm{~b})}$ OFUYATAN Olatokunbo, ${ }^{2(\mathrm{c})}$ NURAIN \\ Suleiman, ${ }^{2(\mathrm{~d})}$ AJAYI Samuel, ${ }^{2(\mathrm{e})}$ Oti Miracle N.
}

\begin{abstract}
In a bid to improve sustainability in road construction and reduce the cost of road construction, there is a need for a green alternative. This research improved the geotechnical properties of tropical lateritic soil using Bamboo Straw Ash (BSA). The lateritic soil was stabilized with increasing percentage of BSA at $0 \%, 2 \%, 4 \%, 6 \%, 8 \%, 10 \%$, and $12 \%$. The index properties, Compaction (Maximum moisture content, Maximum dry Density), CBR, of the soil samples with BSA were evaluated. Response Surface Analysis was used to model the mathematical relationship between the atterberg limit and the CBR of the BSA stabilized soil sample. The plasticity index of the unstabilized soil sample was 14.01 upon the addition of $16 \%$ BSA, the plasticity index reduced to 10.73 which showed an improvement in the soil index properties. The CBR increased from $26.38 \%$ to $30.2 \%$ at $0 \%$ and $8 \%$ respectively which signifies an improved strength. From the Respons Surface Analysis, the highest plasticity index achievable with BSA stabilization is 27.18. The model equation showed that the plasticity index and plasticity limit have a positive relationship with the CBR. Ultimately, the use of BSA provides a cost-effective and green alternative to lateritic soil stabilization in road construction.
\end{abstract}

Keywords: Bamboo straw ash, soil stabilization, strength properties, compaction, Pavement material

\section{Introduction}

The soil is an important material in highway construction but it is also the major cause of pavement failures. Although pavements fail from the top, pavement systems generally start to deteriorate from the bottom (subgrade), which often determines the service life of a road (Hijab, 2012). These failures are mostly due to the use of soil with insufficient strength to carry traffic wheel load applied on it. Improvement is therefore necessary in such cases, this leads to the concept called soil stabilization.

Soil stabilization is any treatment whether technical or compactive, applied to improve the engineering properties of the soil (strength, waterproofing, durability etc.). Stabilization of soil is employed when it is more economical to overcome a deficiency in a readily available material than to bring in one that fully complies with the requirements of the specification for the soil (Ola, 1975). There are various chemical materials that have been used in the past for this process. Lime and cement are the oldest stabilizers used. These materials have proven to be though efficient but expensive and unsustainable hence the necessity to find partial or total replacements for them. With the

\footnotetext{
1, 2(b), 2(e) Department of Civil Engineering, Covenant University Ogun State, Nigeria.

1(b) Department of Civil Engineering, Federal University of Technology, Akure, Nigeria

2(c),2(d) Nigeria Building and Road Research Institute, Ota.

${ }^{1}$ Corresponding Author
} 
waste to wealth initiative and the nation's alertness to economic resource management, biomass waste has been reported to be suitable for such replacements. These include Rice Husk Ash (Chungsangunsit et al, 2007), Bamboo Leaf Ash (Dwiveldi et al, 2006), Palm Fruit Ash (Olonode, 2010), Locust Bean Pod Ash (Adama and Jimoh, 2011), Cement Cassava Peel Ash (Salau et al, 2012), Corn Husk Ash (Adesanya and Raheem, 2009) and Corn Cob Ash (Akinwumi and Aidomojie, 2015), (Yinusa and Jimoh, 2014).

Bamboo has a very long history with human kind. Bamboo chips were used to record history in ancient China. It has also been widely used in building applications, such as flooring, ceiling, walls, windows, doors, fences, housing roofs, trusses, rafters, and purlins; it is also used in construction as structural materials for bridges, water transportation facilities, and skyscraper scaffoldings. However bamboo straw may constitute a nuisance with no economic benefit in areas where the need for its eradication is important. This research provides another economic and engineering usage for bamboo straw ash in road construction. This is in an attempt to improve the strength of pavement interlayer material and also reduce the cost of road construction.

\section{Methodology}

\subsection{Materials}

The Bamboo straws were obtained locally from a shed situated in Sabon Gari local government area in Kawo, Kaduna state. The Bamboo straws were collected, airdried and burnt at a controlled temperature. The ash was collected in sacks and transported to the soil mechanics research laboratory in the Kaduna Polytechnic. The ash was then passed through the BS No 200 sieve $(75 \mu \mathrm{m})$ to meet the requirements of ASTM class N pozzolans (ASTM D4318-10e1) as reported by Head in (1994). The chemical analysis of the bamboo straw ash was carried out using Flame Photometer and the Atomic Absorption Spectrophotometer (Pye-Unicam Model SP 1900). Portable water from Kaduna Polytechnic was used all through the research.

\subsection{Test and Methods}

The moisture content was carried out according to ASTM D 2216 - Standard Test Method for Laboratory Determination of Water (Moisture) Content of Soil, Rock, and Soil-Aggregate Mixtures). The Particle size distribution test was carried out in accordance with BS1377 (1990). The atterberg limit and strength index test was carried out in accordance with (BS 1990b) part 4.

\section{Results and Discussion}

\subsection{Oxide Composition and Seive Analysis}

The basic oxides contained in the soil samples indicate the presence of $\mathrm{Fe}_{2} \mathrm{O}_{3}$, $\mathrm{Al}_{2} \mathrm{O}_{3}$ and $\mathrm{SiO}_{2}$ (Table 2). This from literature have been shown to be the major oxides which indicate lateritic soils but their various quantities in the soil vary, due to laterization (Ola, 1983, Akinwumi, 2015). The chemical composition of the Bamboo straw ash showed that the material is pozzolanic in nature and have the attributes of improving the strength of soil as seen in Table 3.1. 
Table 3.1: Chemical Composition of the Soil Sample and Bamboo Straw Ash

\begin{tabular}{lll}
\hline Composition (\%) & Kaduna Lateritic soils & Bamboo straw ash (BSA) \\
\hline $\mathrm{SiO}_{2}$ & 34.60 & 33.85 \\
$\mathrm{SO}_{3}$ & - & 4.94 \\
$\mathrm{~K}_{2} \mathrm{O}$ & & 34.70 \\
$\mathrm{Na} 2$ & & 9.70 \\
$\mathrm{CaO}$ & 0.25 & 8.13 \\
$\mathrm{MgO}$ & 0.56 & 0.46 \\
$\mathrm{TiO}_{2}$ & & 0.16 \\
$\mathrm{MnO}$ & & 0.21 \\
$\mathrm{Fe}_{2} \mathrm{O}_{3}$ & 2.20 & 1.95 \\
$\mathrm{Cl}$ & & 4.61 \\
$\mathrm{Al}_{2} \mathrm{O}_{3}$ & \\
$\mathrm{Mn}_{2} \mathrm{O}_{5}$ & 25.80 & \\
\hline
\end{tabular}

The Particle size distribution of the soil sample is as seen in figure 3.1. The result of the AASHTO soil classification showed that the soil is A-7-6 soil. It is yellowish brown in colour. This colouration may be due to the percentage of iron oxide content in the soil. The particle size analysis of the sample was seen to have a high percentage of clay and is rated as fair-poor material for a subgrade (Nigeria Specification for Bridges and Road Design, 1997) hence the need for soil stabilization or soil replacement is required.

\section{Particle size Distribution Curve}

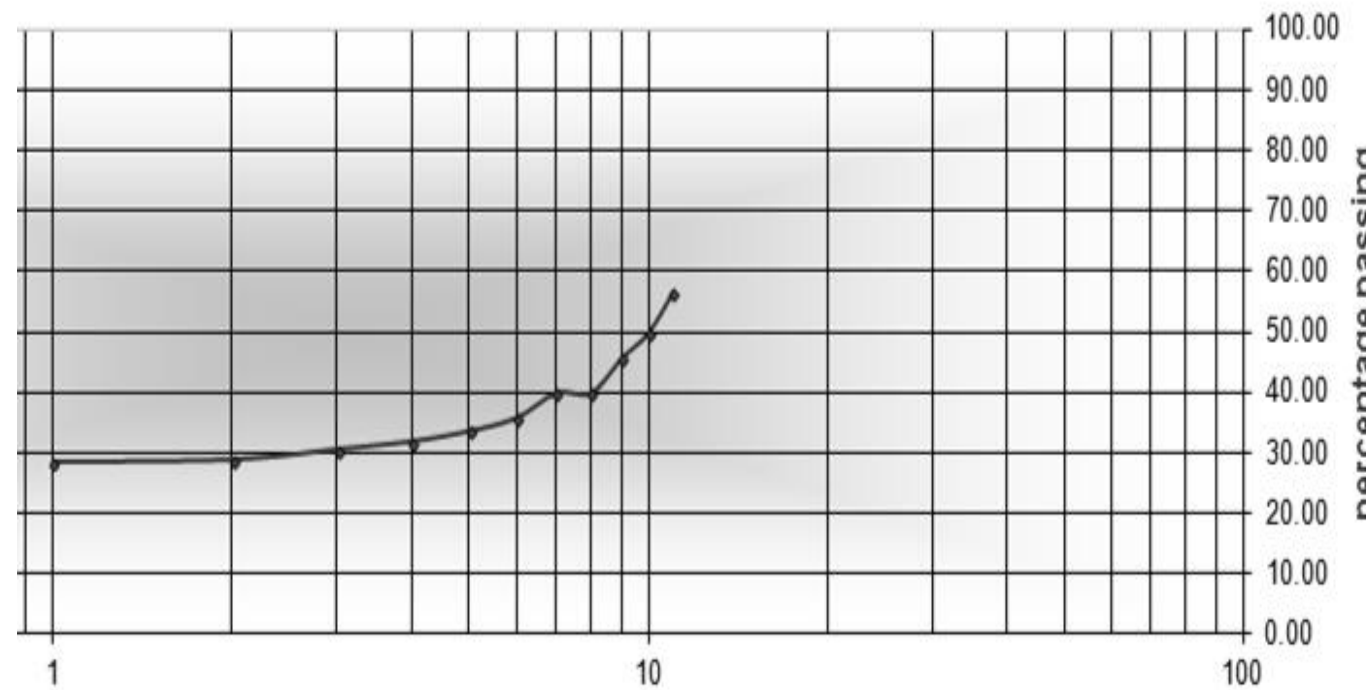

B.S. Sieve Sizes.

Figure 3.1: Sieve Analysis of the Soil Sample 


\subsection{Geotechnical Properties of the Unstabilized Soil Sample}

The preliminary assessment of the soil sample is as indicated in Table 3.2. The atterberg limit of the soil in the form of liquid limit, plastic limit, and the plasticity index was 42, 27.99 and 14.01 (Table 3.4). These properties according to the requirement of Nigeria Bridges and Road design manual is good as an embankment or as a subgrade material. Therefore, there is a need for the improvement of the geotechnical properties of the soil to make it suitable as a sub-base and base material. Accordingly, the CBR value of 26.38 is an indication of the strength index of the soil, the result showed that the soil satisfies the criteria for an embankment or subgrade material.

Table 3.2: Geotechnical Properties of the Unstabilized Soil Sample

\begin{tabular}{ll}
\hline Properties & Quantity/description \\
\hline Natural Moisture Content (\%) & 14.02 \\
Liquid Limit (\%) & 42.00 \\
Plastic Limit (\%) & 27.99 \\
Plastic Index (\%) & 14.01 \\
AASHTO Soil Classification System & A-7-6 \\
Group index & 1 \\
Maximum Dry Unit Weight & 1.81 \\
Optimum Moisture Content (\%) & 15.18 \\
CBR (\%) & 26.38 \\
\hline
\end{tabular}

\subsection{Atterberg Limit of the Stabilized Soil Sample}

The atterberg limit of the stabilized soil indicates that as the percentage of BSA increases the plasticity index of the soil reduces. The reduction in the plasticity index indicates an improvement in the soil index properties. The plasticity index of the unstabilized soil sample was 14.01 upon the addition of $16 \%$ BSA, the index reduces to 10.73 which showed an improvement in the soil index properties as indicated by Whitlow, (1995). 


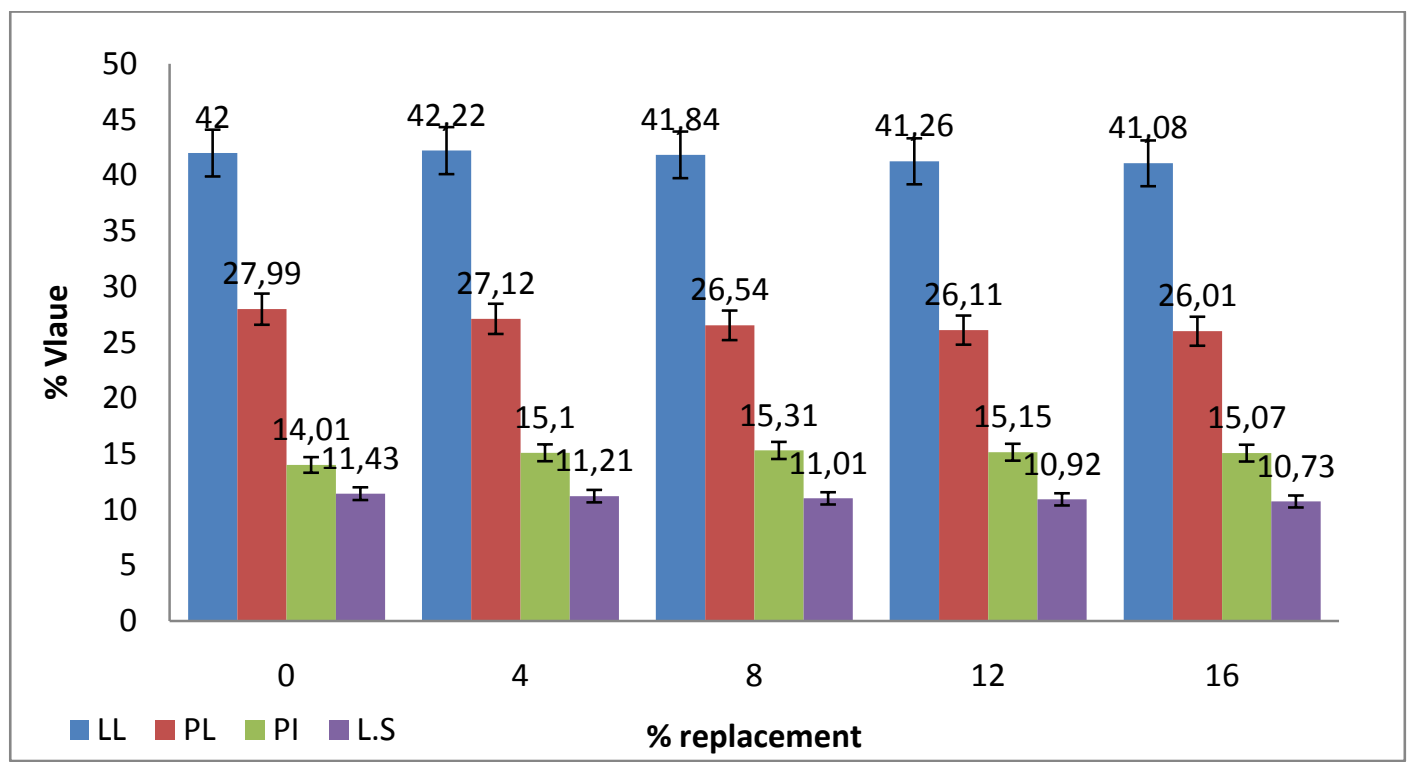

Figure 3.2: Atterberg limit of the Stabilized soil sample

\subsection{Strength Index}

Stabilization of lateritic soil sample with $0 \%-6 \%$ BSA is as represented in figure 3.3. The result indicates a slight decrease in the maximum dry density (MDD) during compaction. Then, with the addition of $8 \%$ BSA, there was an increase in the MDD. The final addition of $16 \%$ lime indicated a decrease in MDD.

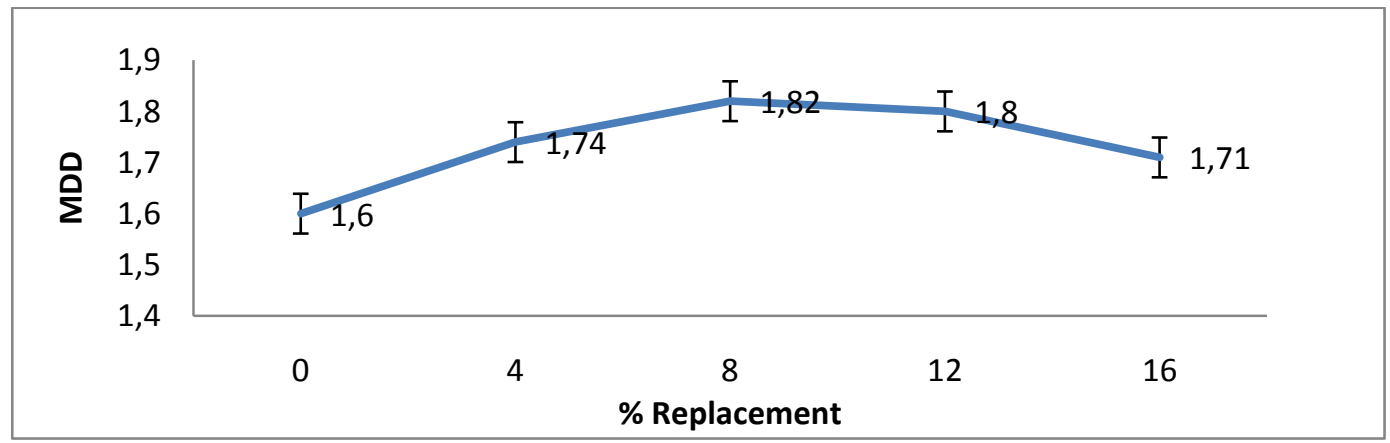

Figure 3.3: Maximun Dry Density of the Stabilized sample

The Optimum moisture content, on the other hand, indicated an increase between $8 \%$ $12 \%$ BSA and then from $12-16 \%$, there was a decrease in OMC. 


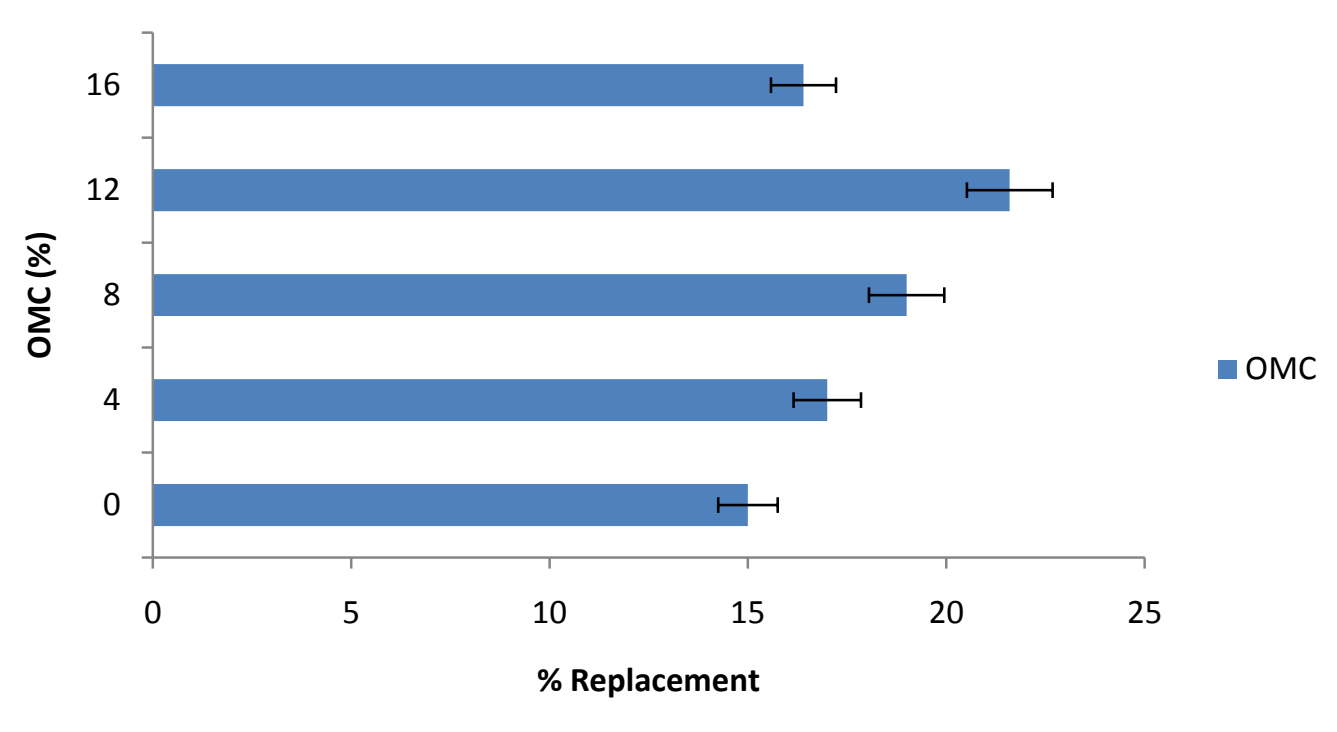

Figure 3.4: Optimum Moisture Content of the Stabilized Sample

\subsection{CBR}

The CBR value of the stabilized soil is as shown in Figure 3.5. From the figure, the CBR increased from $26.38 \%$ to $30.2 \%$ at $0 \%$ and $8 \%$ respectively. This is an indication of improved strength. The improved strength is as a result of the structural modification of the soil structure based on the pozzolanic properties of the BSA.

However, at percentages higher that $8 \%$ the $\mathrm{CBR}$ value reduced. At $8 \% \mathrm{CBR}$ value recorded was good enough for subbase material. Based on the General Specification for roads and bridges design manual, the soil is suitable for subbase and base material.

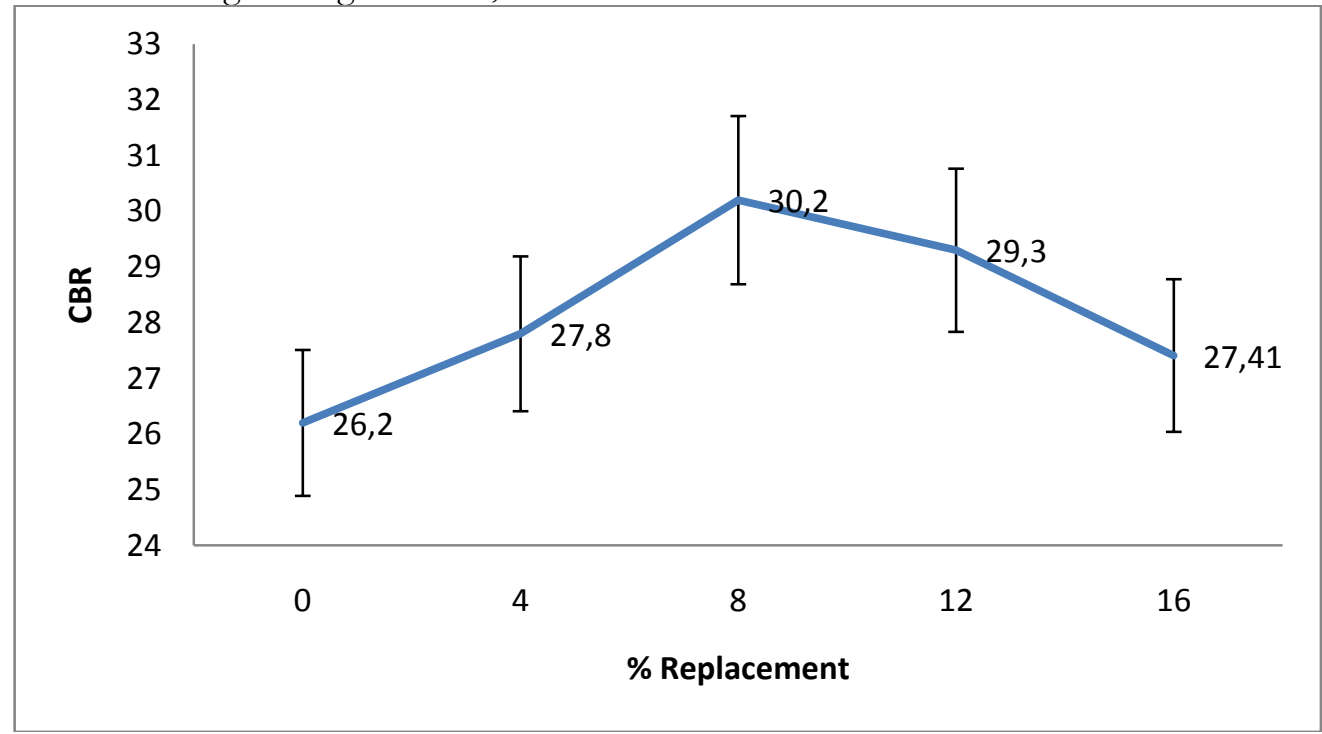

Figure 3.5: CBR value of the stabilized sample 


\subsection{Modelling the Relationship between the Index Properties}

Equation 1 shows the relationship between the strength index (CBR) and the atterberg limit. From the equation, plasticity index and plasticity limit have a positive relationship with the CBR. This means that the higher the PI and PL the higher the CBR of the soil when stabilized with BSA. However, LL had a negative relationship with the CBR of the oil when stabilized with BSA. The R2 value of 0.87 signifies the robustness of the model developed as seen in 3.3 .

$C B R=118.25+4.53 P . I+3.39 P L-5.96$ L.L ------ Equation 1

\begin{tabular}{llll}
\hline Std. Dev. & $\mathbf{0 . 2 4 3 9 8}$ & R-Squared & $\mathbf{0 . 9 9 3 8 2 7}$ \\
\hline Mean & 28.268 & Adj R-Squared & 0.875306 \\
C.V. & 0.863095 & Pred R-Squared & N/A \\
PRESS & N/A & Adeq Precision & 16.36395 \\
\hline
\end{tabular}

\subsubsection{Response Surface Analysis of the Index Properties}

The response surface analysis of the index properties is as seen in Figure 3.6 and 3.7. The result of the analysis showed that the stabilization of A-7-6 soil with BSA index properties is been altered based on the percentage of BSA added. From the analysis, the highest plasticity index achievable with BSA stabilization is 27.18. The highest liquid limit achievable with BSA stabilization is 41.08 as seen in figure 3.6 and 3.7. This to a very large extent will aid researchers, engineers and highway engineers on the optimum index property expected using BSA in the stabilization of lateritic soil.

\section{DESIGN-EXPERT Plot}

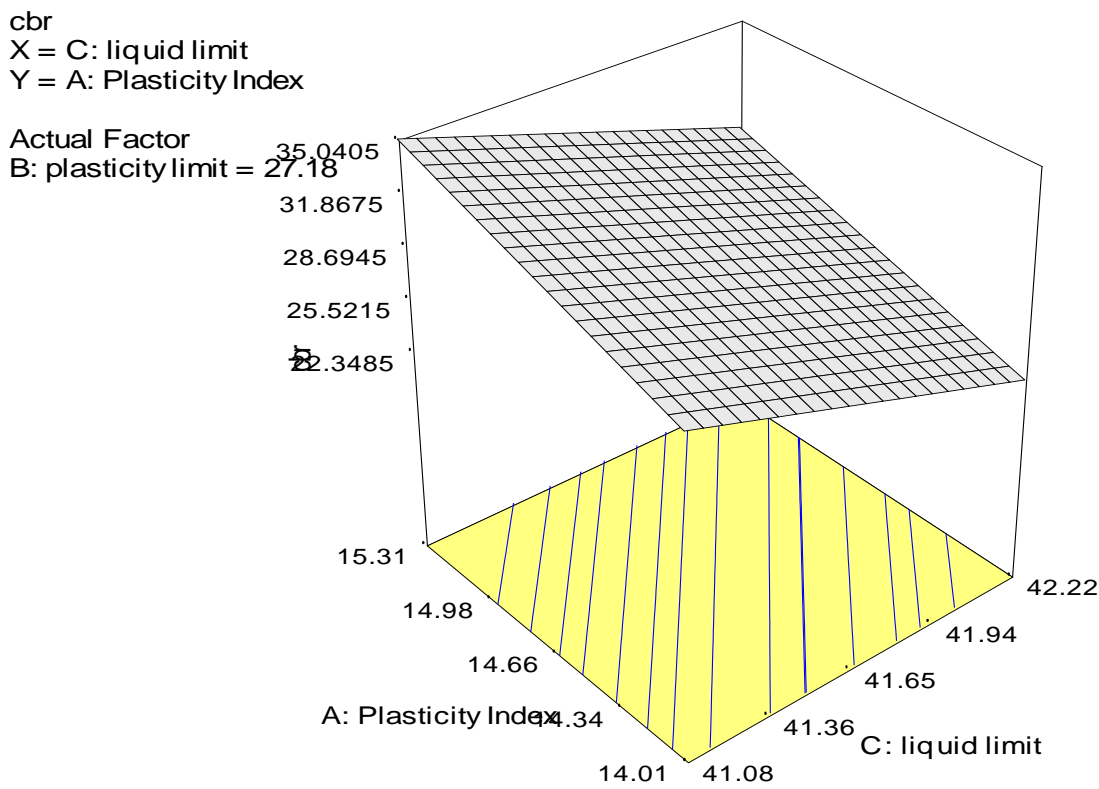

Figure 3.6: Response Surface View of Plasticity Index Versus Plasticity limit 


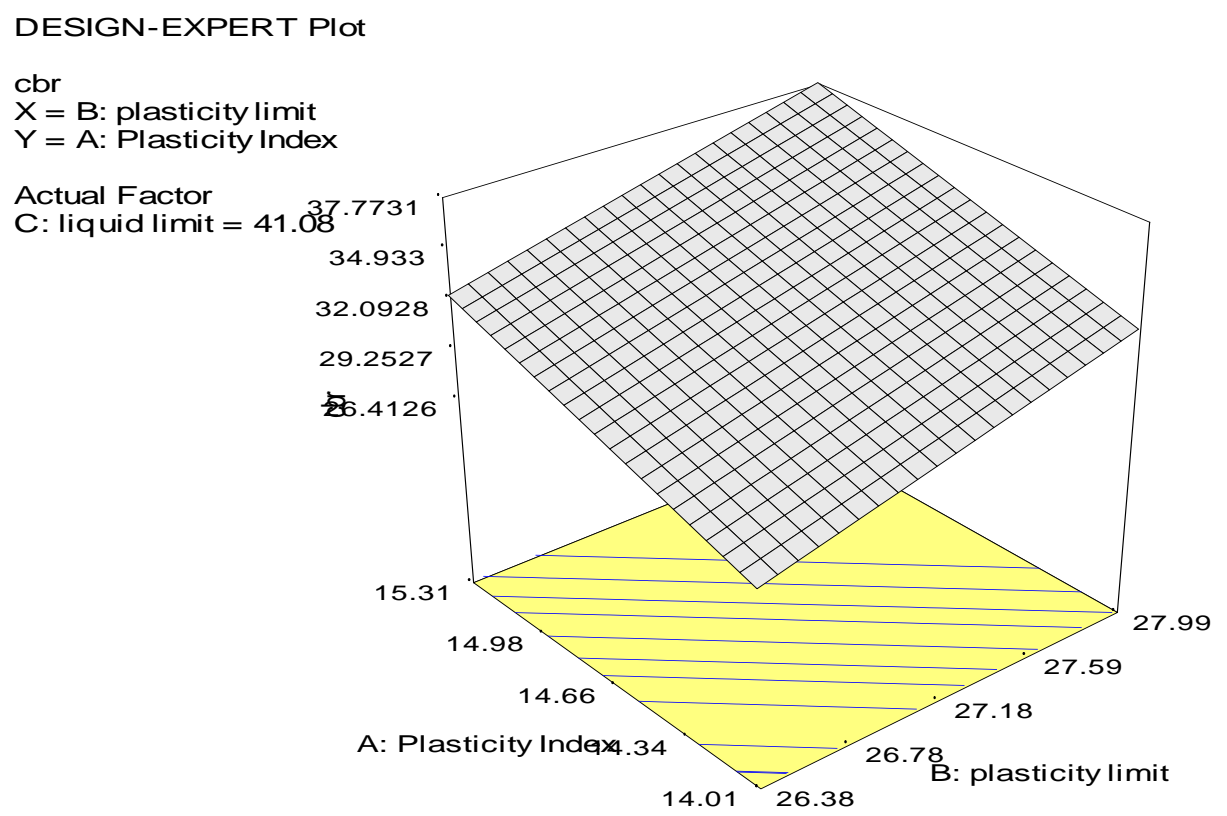

Figure 3.7: Response Surface View of Plasticity Index Versus Plasticity limit

\section{Conclusion}

This experimental research assessed the utilization of Bambo straw Ash in the stabilization of tropical lateritic soil from Kaduna, Northern Nigeria. This was done with special focus on the index properties. Therefore, plasticity limit, liquid limit and plasticity index properties of the soil was assessed. The strength index of the soil was also espoused. The result of the experimental research showed that:

i. The atterberg limit of the soil in the form of liquid limit, plastic limit, and the plasticity index was 42, 27.99 and 14.01

ii. The plasticity index of the unstabilized soil sample was 14.01 upon the addition of $16 \%$ BSA, the plasticity index reduced to 10.73 which showed an improvement in the soil index properties

iii. The highest liquid limit achievable with BSA stabilization is 41.08

iv. From the analysis, the highest plasticity index achievable with BSA stabilization is 27.18

$\mathrm{v}$. The model equation showed that the plasticity index and plasticity limit have a positive relationship with the CBR. This means that the higher the PI and PL the higher the CBR of the soil when stabilized with BSA.

vi. However, LL had a negative relationship with the CBR of the oil when stabilized with BSA. 


\section{Recommendation for Future Research}

Future research should focus on the effect of Bamboo Straw ash on both lime and cement stabilized soil, which the authors are already working on.

\section{References}

Adama Andrew Y., Yinusa A. Jimoh and Stephen S. Kolo (2013). Effect of Locust Bean Pod

Ash on Compaction Characteristics of Weak Sub Grade Soils. International Journal of Engineering Science Invention ISSN (Online): 2319 - 6734, ISSN (Print): 2319 - 6726 www.ijesi.org Volume 2 Issue 1 January. 2013 PP.25-30 www.ijesi.org 25

Adesanya, D. A., and Raheem, A. A. (2009a). A study of the workability and compressive strength characteristics of corn cob ash blended cement concrete. Construction and Building Materials, 23, pp 311-317. 3 .

Akinwumi I.I., Aidomojie O.I. (2015). Effect of Corncob ash on the geotechnical properties of

Lateritic soil stabilized with Portland cement International Journal Of Geomatics And Geosciences Volume 5 , No 3 ,

ASTM D4318 - 10e1.Standard Testb Methods fo Liquid Limit, Plastic Limit and Plasticity Index.

BSI (1990). Stabilized materials for civil engineering purposes: General requirements,

sampling, sample preparation and tests on materials before stabilization. British Standards Institution, BS 1924: Part 1: London.

Chungsangunsit, T., Gheewla, H., and Patumsawad, S., (2009). Emission Assessment of Rice

Husk Combustion for Power Production. World Academy of Science, Engineering and Technology Journal.

Vol 53 p 1070 - 1075. Available at www.waset.org/journals/waset [March 4 2012]

Dwivedi, V.N., Singh, N.P., Das, S.S. and Singh N.B. (2006). A new pozzolanic material for the

cement industry: bamboo leaf ash. International Journal of Physical Sciences Vol. 1 (3), pp. 106 - 111.

Available on line at www.academicjournals.org/IJPS

Head, K. H. (1994). Manual Of Soil Laboratory Testing, Vol. 2, Pentech Press, London.

Hijab Mahmoud1, Z. A. (2012). Road Pavement Failure Induced By Poor Soil Properties Along Gombi-Biu. Journal Of Engineering And Applied Science .

Nigerian General Specification (1997). Roads and Bridges. Federal Ministry of Works, Lagos.

Ola, S.A. (1983). Tropical Soils in Engineering Practice. Balkema Publishers, Rotterdam, Netherlands.

Ola, S. A. 1975. "Need for estimated cement requirements for stabilization of laterite soils."

Journal Transportation Engineering Division, ASCE, 100_2_, 379-388.

Olonode, K.A. (2010). Prospect of Agro-By-Products As Pozzolans in Concrete For Low-Cost

Housing Delivery in Nigeria. Proceedings of the International Conference of the Obafemi Awolowo

University, Faculty of Technology. Vol. 1 pp. $217-221$.

Salau, M.A., Ikponmwosa, E.E., and Olonode, K.A. (2012). Structural Strength Characteristics

of CementCassava Peel Ash Blended Concrete. Journal of Civil and Environmental Research. IISTE Vol.2,

No 10, 2012.Available at www.iiste.org

Whitlow, R (1995). Basic Soil Mechanics. 3rd edition. Addison Wesley Longman Limited,

Edinburgh Gate.Characterisation of Mineral Wastes, Resources and Processing technologies

Yinusa A. Jimoh1, O. A. (2014). An Evaluation of the Influence of Corn Cob Ash on the

Strength. Civil and Environmental Research 